\title{
Abiogenic formation of $\mathrm{H}_{2}$, light hydrocarbons and other short-chain organic compounds within the serpentinite mud volcanoes of the Marianna Trench
}

\author{
Olivier Sissmann ${ }^{1, *}$, Roy Price $^{2}$, Marcus Elvert ${ }^{3}$, Verena B. Heuer ${ }^{3}$, Xavier Prieto ${ }^{3}$, \\ Christophe Monnin ${ }^{4}$, Virgile Rouchon ${ }^{1}$, Sonia Noirez ${ }^{1}$, Valérie Beaumont ${ }^{1}$, Jérémie \\ Ammouïal $^{1}$, Eric Kohler ${ }^{1}$, Catriona Menzies ${ }^{5}$, Jeffrey Ryan ${ }^{6}$, and Ken Takai ${ }^{7}$ \\ ${ }^{1}$ IFP Energies Nouvelles, Rueil-Malmaison Cedex, France \\ ${ }^{2}$ School of Marine and Atmospheric Sciences, Stony Brook University, Stony Brook, USA \\ ${ }^{3}$ MARUM - Center for Marine Environmental Sciences, University of Bremen, Germany; \\ ${ }^{4}$ Geosciences Environnement Toulouse, University Paul Sabatier, France ; \\ ${ }^{5}$ School of Ocean and Earth Science, University of Southampton, UK \\ ${ }^{6}$ School of Geosciences, University of South Florida, USA \\ ${ }^{7}$ Department of Subsurface Geobiological Analysis and Research, JAMSTEC, Japan
}

\begin{abstract}
Serpentinite-hosting mud volcanoes, located in the Marianna forearc subduction zone, were drilled during IODP Expedition 366. Recovered samples from Asùt Tesoru seamount provide new insights on the generation of organic matter in deep environments. Short-chain alcohols, volatile fatty acids and light hydrocarbons are produced within hyperalkaline pore fluids $(\mathrm{pH} 12.5)$ rich in $\mathrm{H}_{2}$. The stable isotope values of those species show heavy $\delta^{13} \mathrm{C}$ values, suggesting a formation process through Fischer-Tropsch-Type reactions. This close isotopic study brings new constraints on the reaction pathways leading to the formation of not only light hydrocarbons, but also of short-chain organic molecules. These compounds may serve as precursors of building blocks essential to life in deep oceanic settings.
\end{abstract}

\section{Introduction}

Though hydrothermal fluids have been extensively studied in various geological environments (e.g. mid-ocean ridges), the origin of light hydrocarbons and other shortchain organic compounds in those settings remain vividly debated. We report in this study a full set of carbon and hydrogen isotope compositions, to help shed new light on the formation processes of methane and other low molecular weight carbon compounds in deep hydrothermal environments.

IODP expedition 366 (December 2016 - February 2017) recovered cores and associated pore fluids from drilling operations into three mud volcanoes located in the Marianna forearc. Asùt Tesoru Seamount (informally called Big Blue Seamount) is a submarine

\footnotetext{
*Corresponding author: olivier.sissmann@ifpen.fr
} 
serpentinite mud volcano which lies about $72 \mathrm{~km}$ from the trench axis, with the subducting slab located about $18 \mathrm{~km}$ below its summit [1], at an estimated temperature range of 250 $300^{\circ} \mathrm{C}$ (Figure 1a). It is one of the largest seamounts on the Mariana forearc, with a diameter of $\sim 50 \mathrm{~km}$ and over $2 \mathrm{~km}$ high. It may have been active since the Eocene, based on analysis of two serpentine-bearing sediment intervals immediately above Eocene basement, recovered during Deep Sea Drilling Project (DSDP) Leg 60 at Site 459 [2].

Within the seamounts, serpentinization is an active process, which consists of the hydration of mafic or ultramafic minerals. When it occurs, $\mathrm{Fe}^{2+}$ is released from the primary silicate mineral, it oxidizes by reducing water, generating $\mathrm{H}_{2}$ and high $\mathrm{pH}$ fluids:

$$
2 \mathrm{Fe}^{2+}+2 \mathrm{H}_{2} \mathrm{O} \rightarrow 2 \mathrm{Fe}^{3+}+2 \mathrm{OH}^{-}+\mathrm{H}_{2}
$$

Subsequently, the formation of organic matter may occur, through the interaction of $\mathrm{H}_{2}$ with a source of inorganic carbon, such as the Sabatier reaction:

$$
\mathrm{CO}_{2}+2 \mathrm{H}_{2} \rightarrow \mathrm{CH}_{4}+2 \mathrm{H}_{2} \mathrm{O}
$$

Fischer-Tropsch-Type reactions have been extensively studied as an industrial process in gaseous media. However, their occurrence in natural geological systems remain vividly debated. The appropriate temperature, $\mathrm{pH}$ or redox conditions of the aqueous medium, as well as the reaction pathways leading to the formation of light alkanes, remain unknown.

\section{Methods}

Drilling operations on the Joides Resolution vessel recovered cores from the summit of the seamount, located around 1200 meters below sea level, and from the flank, with the lowest drill located close to the seafloor, 4000 meters below sea level. The cores were brought back on deck 5 meters at a time. Once the cores were on deck, free gas pockets formed within the liner under gas expansion at atmospheric pressure. The liner was thus pierced and sampled for headspace analysis with a gastight syringe. Those gas samples were later analysed in the lab through GC for quantification, GC-C-IRMS for stable isotope composition in $\delta^{13} \mathrm{C}$ and $\delta \mathrm{D}$, and noble gas mass spectrometry.

A whole-round core sample (from 10 to $20 \mathrm{~cm}$ long) was also taken immediately after core sectioning on deck for subsequent extraction of interstitial water. LC-IRMS was used to analyse $\delta^{13} \mathrm{C}$ of dissolved organic species. TOC and $\mathrm{S}$ concentrations were determined using a prototype Rock-eval 6 apparatus with a sulphur enabled module.

\section{Results and Discussion}

Recovered samples from Asùt Tesoru seamount provide new insights on the generation of organic matter from fluid-rock interactions in deep oceanic environments, through FischerTropsch-Type (FTT) reactions. The reduction of water by ferrous iron (see equation 1) has produced hyperalkaline pore fluids ( $\mathrm{pH}$ up to 12.5) rich in $\mathrm{H}_{2}$ (up to $2 \mathrm{mM}$ ). Those fluids are prone to react with the accompanying DIC (up to $4.5 \mathrm{mM}$ ). Varying amounts of sulfide/oxide minerals observed within the mud may have catalyzed the reaction $(100 \mathrm{ppm}$ to $3 \mathrm{wt} . \%$ total sulphur). This situation is ideal to produce carbon species like volatile fatty acids (VFAs), or short-chain alcohols. Those compounds are potential intermediates that form before the generation of light hydrocarbons (see Figure 1c). 


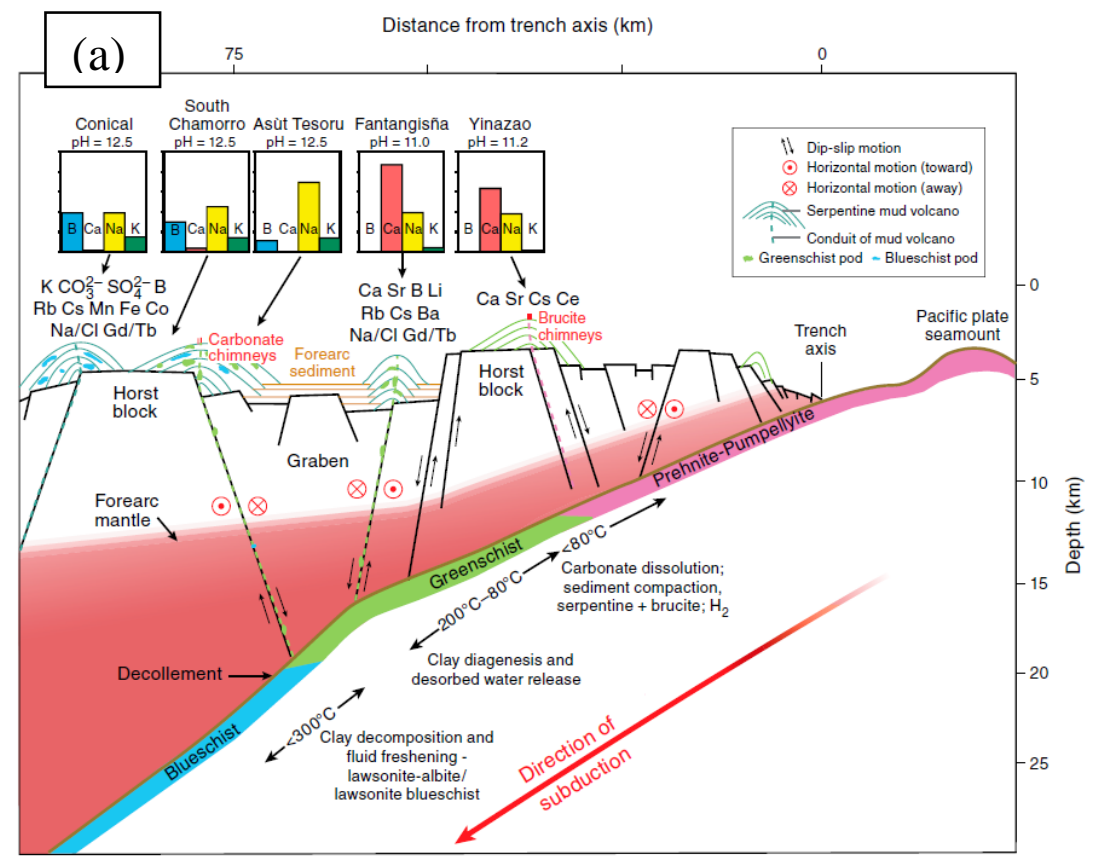

(b)

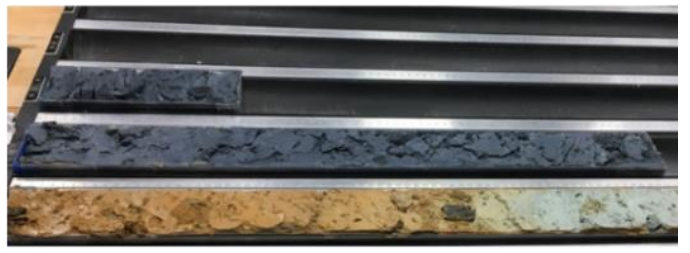

(c)

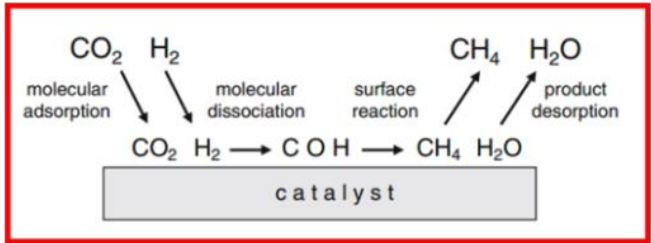

Fig. 1. (a) Drilling area representing the mud volcanoes in the Marianna subduction zone; Asùt Tesoru seamount is the farthest away from the axis of the trench $(75 \mathrm{~km})$, and has deep-source fluid chemistry [3]; (b) Cores of reduced serpentines, rich in sulfides and organic matter. (c) schematic of a potential Fischer-Tropsch-Type (FTT) reaction generating organic matter abiogenically.

The complete set of stable carbon isotope information of those compounds was acquired. This close isotopic study brings new constraints on the reaction pathways allowing to form precursors of building blocks essential to life in subduction zones. VFAs are mostly composed of formate and acetate (up to 100 and $40 \mu \mathrm{M}$ ), associated with methanol (up to $30 \mu \mathrm{M}$ ). These short-chain components have extreme carbon isotope 
compositions, with heavy $\delta^{13} \mathrm{C}$ values of up to $+4.8 \%$ for formate, $-8.0 \%$ for acetate and $+2.3 \%$ o for methanol, strongly suggesting an abiogenic origin and formation during $\mathrm{CO}_{2}$ reduction with $\mathrm{H}_{2}$. The gas phase of the serpentine mud is composed of a mix of $\mathrm{H}_{2}$ and $\mathrm{CH}_{4}$ (up to $95 \%$; see Figure 2). Associated molecular composition monitored via $\mathrm{C}_{1} / \mathrm{C}_{2+}$ ratios barely varies down to $100 \mathrm{mbsf}$, implying low or even absent microbial activity. Corresponding $\delta^{13} \mathrm{C}$ values of methane as heavy as $-16 \%$ are in good agreement with reported abiogenic values. In addition, measured ${ }^{3} \mathrm{He}$ concentration and extrapolated ${ }^{3} \mathrm{He} / \mathrm{CO}_{2}$ ratios suggest a primarily mantle-derived inorganic carbon source. The fractionation between the $\delta \mathrm{D}$ values of $\mathrm{CH}_{4}, \mathrm{H}_{2}$ and $\mathrm{H}_{2} \mathrm{O}$ was also measured, and can be used to discuss potential temperature formation conditions at isotopic equilibrium.

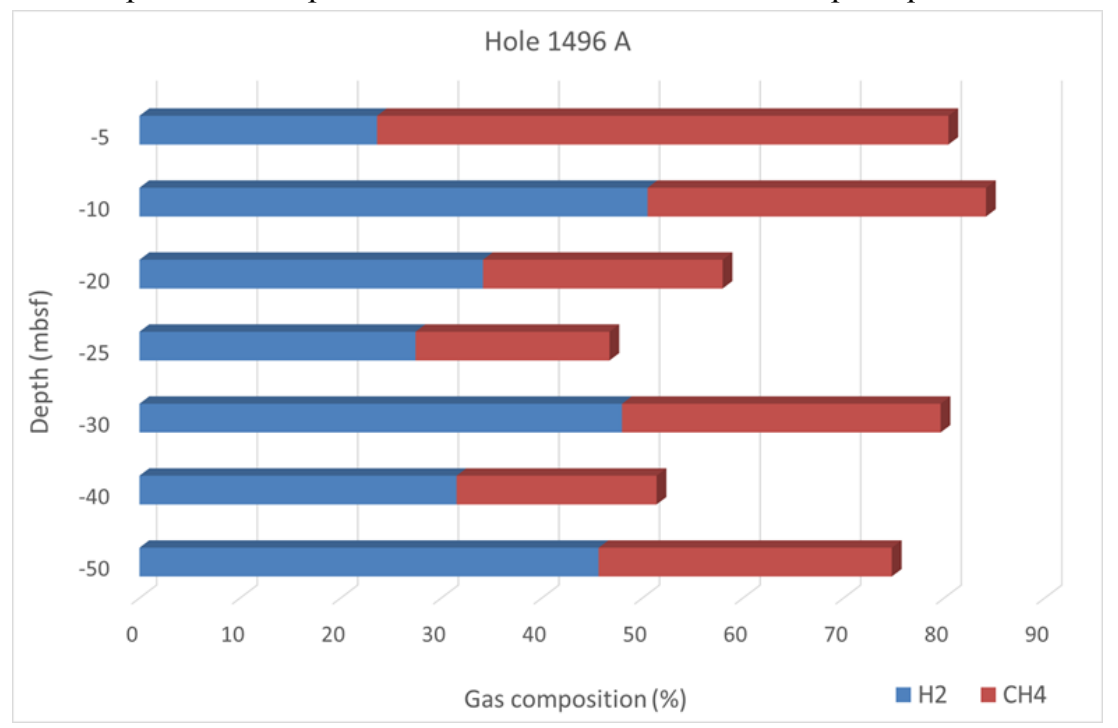

Fig. 2. Gas Composition (in \%) on Asùt Tesoru Summit, versus depth (in meters below sea floor).

\section{Conclusions}

The dataset acquired on samples collected from IODP expedition 366 thus points to the abiogenic formation of low molecular weight organic compounds in the Marianna forearc. Furthermore, it brings new constraints on the reaction pathways leading to the formation of precursor molecules essential to life in serpentinizing environments.

Acknowledgements: The authors wish to thank all IODP exp 366 members, mission co-chiefs Patricia Fryer and Geoff Wheat, as well as IODP officer Trevor Williams, for making the exploration of the Marianna forearc a reality. Olivier Sissmann thanks IODP France for funding on-shore research.

\section{References}

1. A.J. Oakley, B. Taylor, and G.F. Moore, Geoch., Geoph., Geosys., 9 (6):Q06003. (2008)

2. A. Desprairies, In Hussong, D.M., Uyeda, S., et al., Initial Reports of the Deep-Sea Drilling Project, 60, 455-466 (Washington, DC, U.S. Government Printing Office, 1982)

3. P. Fryer et al., Proceedings of the International Ocean Discovery Program, 366, 01-23 (2018) 